\title{
Combining a dynamic battery model with high-resolution smart grid data to assess microgrid islanding lifetime
}

\author{
Robert L. Fares ${ }^{1, *}$, Michael E. Webber ${ }^{1}$ \\ Department of Mechanical Engineering, The University of Texas, Austin, Texas 78712
}

\begin{abstract}
In this paper, we use experimental data collected from an Austin, Texas smart grid test bed with a system-level battery energy storage model to assess the lifetime of batteries in a microgrid operating in islanded mode during a distribution-level outage. We consider a hypothetical microgrid consisting of 21 single-family detached homes and three transformer-level community energy storage (CES) battery units ranging in size from $25 \mathrm{kWh}$ to $75 \mathrm{kWh}$. To describe the performance of CES batteries, we implement a dynamic behavioral circuit model capable of describing voltage transients and ratecapacity effects. We use one-minute electricity production and consumption data collected from the smart grid test bed in 2012 to assess how the timing of an electric outage affects the islanding lifetime of a residential microgrid. We contrast our results with the average outage duration reported by U.S. electric utilities to quantify how often a residential microgrid could withstand a typical outage. Our results show that increasing the amount of rooftop $\mathrm{PV}$ in a residential microgrid does not significantly increase how often it can withstand an average-duration outage. However, combining PV with CES extends the median islanding lifetime by up to 11.6 hours during morning outages. Based on our results, $50 \mathrm{kWh}$ CES provides the best tradeoff between the cost of a CES system and its reliability benefit, allowing downstream loads to withstand an average-duration outage approximately $93 \%$ of the time.
\end{abstract}

*Department of Mechanical Engineering, The University of Texas at Austin, 204 E. Dean Keeton Street, Stop C2200, Austin, Texas 78712-1591

Email address: robertfares@utexas.edu (Robert L. Fares)

Preprint submitted to Applied Energy

April 7, 2014

(C) 2014. This manuscript version is made available under the Elsevier user license http://www.elsevier.com/open-access/userlicense/1.0/ 
Keywords: Energy Storage, Microgrid, Smart Grid, Solar, Photovoltaics

\section{Introduction and motivation}

With the rapid development of battery energy storage devices and the rising implementation of intelligent electricity distribution technologies, there has been growing interest in distribution-level battery energy storage systems $[1,2,3]$. Energy storage located at the distribution level of the grid can provide useful control services, reduce the cost of delivering electricity during peak-demand hours, integrate local intermittent renewable energy, and isolate a node of the distribution system during an electric outage to form a microgrid [1, 2, 3]. The U.S. Department of Energy defines a microgrid as "a group of interconnected loads and distributed energy resources (DERs) within clearly defined electrical boundaries that acts as a single controllable entity with respect to the grid [and can] connect and disconnect from the grid to enable it to operate in both grid-connected or island mode." [4].

One proposed distribution-level energy storage technology is community energy storage (CES), a $25 \mathrm{~kW}$ battery system located at the distribution transformer [1]. The goal of this paper is to model the state of CES used to isolate downstream electric loads, so that we can approximate how long CES could provide backup power during an outage. It is difficult to gauge how long CES could isolate downstream loads because electric demand often varies widely with ambient temperature, time of day, and other factors. Furthermore, the power load placed on a battery affects its available capacity $[5,6]$. To approximate how long a battery could power a microgrid, information must be known about the power load on the battery and the battery's real-time performance.

To model the performance of CES, we use a dynamic behavioral circuit model [7]. The model has the capability to describe how the voltage and capacity of a battery vary with its duty cycle. These features are important for the purpose of this paper, because a battery powering a microgrid would have a variable load applied to it.

To approximate the load that would be applied to CES powering a microgrid during an electric outage, we use high-resolution electricity data collected by Pecan Street Inc. [8] of Austin, Texas as part of its ongoing smart grid demonstration study [9]. The study utilizes a test bed of 250 modern, green-built homes constructed after 2007, and 160 homes ranging from 10-92 
years in age [10]. The homes are instrumented with electricity, gas, and water metering equipment. Of the 250 homes in the study, 185 are outfitted with rooftop solar photovoltaic (PV) panels [10], which are metered separately from electric demand. For the purposes of this paper, we utilize electric demand and PV generation data with a one-minute time resolution collected from 21 of homes with PV panels over the entirety of 2012.

The remainder of this paper is organized as follows: Section 2 introduces the concept of microgrids and discusses the dynamic battery performance modeling literature; Section 3 discusses how we implement a dynamic battery model to approximate the state of CES powering a microgrid; Section 4 shows how we combine the battery model with empirical electricity data to calculate the islanding lifetime of a microgrid powered by CES; Section 5 shows the results of our analysis; and Section 6 discusses our results and prospects for future work.

\section{Background}

\subsection{Distributed energy resources and microgrids}

For many years, the electric grid has operated within a centralized, energyon-demand paradigm. Electric power is typically produced in a large power station located far away from electricity end users, and then sent over a long distance using high-voltage transmissions lines (electric "highways"). Transmission lines deliver electric power to a substation, which transfers the power to distribution lines (electric "roads") that deliver electricity to end users. The entire grid operates on demand; electricity is instantaneously generated, delivered, and consumed in real-time.

The physical separation between energy sources and energy users is a primary vulnerability that affects electric reliability. Temporary distribution equipment failures that disrupt the flow of current cause all downstream electric customers to lose power. Because these failures are difficult to avoid, a typical U.S. electric customer experiences 1-2 power outages a year, with each outage lasting approximately 2.5-3 hours on average [11].

Beyond the issue of power reliability, today's grid sometimes lacks sufficient power quality for some end users. Transmission and distribution lines behave as inductors when they carry electric power over long distances. Their inductive reactance must be compensated for using banks of capacitors, power electronics, or other equipment to avoid excess reactive power 
flow, which can potentially cause voltage sags, voltage collapse or even a system-wide blackout [12].

Issues such as power quality and reliability have driven interest in a grid with a larger share of DERs, such as energy storage, demand response, microturbines, fuel cells, and PV panels [13, 14, 15]. Because they are located close to electricity customers, DERs have the potential to fundamentally increase electric reliability and power quality. Nevertheless, centrally coordinating and controlling a fleet of DERs poses a challenge to grid operators $[13,14]$. One solution is to lump groups of DERs and electric loads into microgrids $[13,16,17,18]$, which can behave as a single entity capable of operating in both grid-connected and island mode [4].

In this paper, we build on our previous work [19] to evaluate the impact of transformer-level CES coordinating with local PV generation and electric loads to form an islanded microgrid during an electric outage.

\subsection{Battery modeling}

Researchers have developed numerous models to describe the performance of a battery. The literature divides battery models into three major categories: electrochemical models, mathematical models and electrical models. Electrochemical models use fundamental electrochemical and chemical equations to describe the transport and reaction of active species inside a battery. They describe how the concentration of active species at the electrode surface affects the overpotential required to drive an electrochemical reaction to store or release energy [20]. Electrochemical models are primarily used as a design tool to optimize the performance of a battery. Newman and Dees have developed models of this kind for lithium-ion batteries [21, 22].

Mathematical models use semi-analytical or empirical equations to describe the system-level characteristics of a battery, such as capacity, efficiency and voltage. Peukert's law, which describes the relationship between rate of discharge and discharge capacity, is one of the earliest mathematical models $[5,6]$. Other mathematical models describe a battery's non-linear capacity/recovery effects $[23,24,25,26]$ or energy efficiency [27].

Electrical models are equivalent circuit models that describe the systemlevel behavior of a battery using a combination of variable voltage sources, resistors, and capacitors. A number of electrical models have been developed in the literature including Thévenin equivalent circuit models [28, 29, 30], impedance-based models [31, 32, 33], and runtime-based models [34, 35]. A behavioral circuit model developed by Chen and Rincón-Mora combines the 
benefits of many of these models [7]. It accurately describes the nonlinear voltage of a battery, short-term and long-term transient effects, and nonlinear rate-capacity effects.

The objective of this paper is to describe the capabilities of a battery energy storage unit used to isolate downstream loads and provide emergency backup power during a distribution-level outage. In doing so, a large power load in excess of the battery's capacity might be applied for a short period of time. Furthermore, unlike a battery used in typical applications, a battery used for islanding will continue to discharge until its minimum cutoff voltage is reached, where the terminal voltage behavior is highly nonlinear. Thus, it is important to utilize a model capable of describing dynamic ratecapacity effects and end-of-discharge voltage behavior. Chen and Rincón Mora's model combines the benefits of a number of dynamic behavioral circuit models to describe both of these phenomenon without significant added complexity [7]. Thus, we select the behavioral circuit model from [7] for our analysis.

\section{Model development and transformation}

Chen and Rincón-Mora's model describes the state of a battery using two coupled electrical circuits, as shown in Figure 1. The "battery lifetime circuit" on the left-hand side of Figure 1 estimates a battery's state of charge based on the current input, $I_{\text {batt }}$. The capacitor $C_{\text {capacity }}$ integrates the coulombs of charge flowing into and out of the battery, and the resistor $R_{\text {self-discharge }}$ models how state of charge naturally decreases over time in the absence of an external charging current or float voltage. The circuit components combine to produce a voltage at node $V_{\text {SOC }}$ corresponding to the battery's state of charge. The "voltage-current characteristics circuit" on the right-hand side of Figure 1 estimates a battery's terminal voltage based on the current input and state of charge $\left(V_{\mathrm{SOC}}\right.$ from the battery lifetime circuit). The variable potential source $V_{\mathrm{OC}}\left(V_{\mathrm{SOC}}\right)$ models how open-circuit voltage varies with state of charge, and the series resistor $R_{\text {series }}$ and two parallel RC networks consisting of $R_{\text {transient,S }}, C_{\text {transient, } \mathrm{S}}, R_{\text {transient, } \mathrm{L}}$, and $C_{\text {transient,L }}$ model how the battery's terminal voltage dynamically changes under a variable applied current, $I_{\text {batt }}$. Each of these circuit components has parameters defined by a variable function fit to experimental performance data [7]. The details of the experimental procedure for extracting the model parameters are described in the literature [7, 36, 37]. 


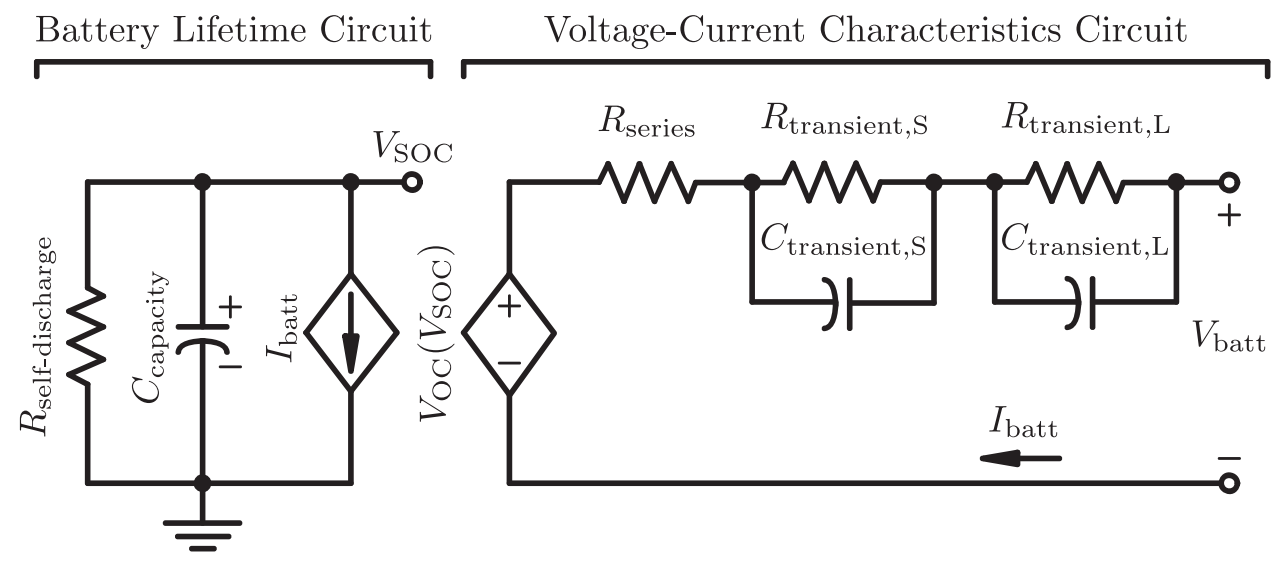

Figure 1: The battery lifetime circuit describes the dynamic nature of a battery's state of charge, and the voltage-current characteristics circuit describes how the terminal voltage of a battery is dynamically affected by state of charge and current load. Figure adapted from [7].

We use this model to describe the performance of a CES unit. Specifications for proposed transformer-level CES are available from American Electric Power, a major U.S. electric utility [1]. The specifications were developed by a consortium of large U.S. electric utilities and other relevant stakeholders under the organization of the Electric Power Research Institute (EPRI). The specifications discuss the size, placement, roundtrip efficiency, energy capacity and power capacity of CES. The given functional specifications for CES are shown in Table 1.

Table 1: Functional specifications for community energy storage were developed by American Electric Power, the Electric Power Research Institute and other relevant stakeholders [1].

\begin{tabular}{cc}
\hline Parameter & Specification \\
\hline Power Capacity & $25 \mathrm{~kW}$ \\
Energy Capacity & 25,50, or $75 \mathrm{kWh}$ \\
AC-AC Roundtrip Efficiency & $>85 \%$ \\
Enclosure Dimensions $(\mathrm{W} \times \mathrm{D} \times \mathrm{H})$ & $38 " \times 40 " \times 35 "$ \\
\hline
\end{tabular}


We assume that CES uses batteries with a lithium-ion chemistry. Based on performance characteristics reported in the literature [38, 40,41], lithiumion is the battery chemistry most likely to meet the CES specification's requirements for roundtrip efficiency and dimensions. Chen and Rincón-Mora experimentally extracted the model parameters for an 850-mAh TCL PL383562 polymer lithium-ion battery cell. We assume that this battery has a similar dynamic character to batteries that would be used in a CES unit. The model parameters for the specified cell are given in the following equations:

$$
\begin{gathered}
C_{\text {capacity }}=3060 \mathrm{~F} \\
V_{O C}=-1.031 e^{-35 V_{S O C}}+3.685+0.2156 V_{S O C}-0.1178 V_{S O C}^{2}+0.3201 V_{S O C}^{3} \mathrm{~V} \\
R_{\text {series }}=0.1562 e^{-24.37 V_{S O C}}+0.07446 \Omega \\
R_{\text {transient }, S}=0.3208 e^{-29.14 V_{S O C}}+0.04669 \Omega \\
C_{\text {transient }, S}=-752.9 e^{-13.51 V_{S O C}}+703.6 \mathrm{~F} \\
R_{\text {transient }, L}=6.603 e^{-155.2 V_{S O C}}+0.04984 \Omega \\
C_{\text {transient }, L}=-6056 e^{-27.12 V_{S O C}}+4475 \mathrm{~F}
\end{gathered}
$$

With the model parameters established, one can build a physical circuit model using software such as Cadence PSpice or MathWorks SimPowerSystems. We transform the physical model into a mathematical model, increasing modeling software compatibility and performance. Kirchoff's circuit laws are used to extract the mathematical equations that describe the dynamic state of the behavioral circuit model components, resulting in the following nonlinear differential equations:

$$
\begin{gathered}
\dot{V}_{S O C}=-\frac{I_{\text {batt }}}{C_{\text {capacity }}} \\
\dot{V}_{\text {transient }, S}=\frac{I_{\text {batt }}}{C_{\text {transient }, S}}-\frac{V_{\text {transient }, S}}{R_{\text {transient }, S} C_{\text {transient }, S}}
\end{gathered}
$$




$$
\begin{gathered}
\dot{V}_{\text {transient }, L}=\frac{I_{\text {batt }}}{C_{\text {transient }, L}}-\frac{V_{\text {transient }, L}}{R_{\text {transient }, L} C_{\text {transient }, L}} \\
V_{\text {batt }}=V_{O C}-I_{\text {batt }} R_{\text {series }}-V_{\text {transient }, S}-V_{\text {transient }, L}
\end{gathered}
$$

Using Equations 8-11, the model for an individual cell can be readily implemented in any modeling platform capable of numerically integrating coupled nonlinear differential equations. We implement the model for an individual battery cell in MathWorks Simulink.

Assuming that battery cells can be ideally lumped, the model for an individual cell can be scaled up to describe CES units with specifications matching those in Table 1 . We develop models for $25 \mathrm{kWh}, 50 \mathrm{kWh}$, and 75 kWh CES units. For each of these units, we calculate the number of battery cells required so that a discharge from "full" $\left(V_{S O C}=1, V_{\text {cell }}=4.2 \mathrm{~V}\right)$ to "empty" $\left(V_{\text {cell }}=3 \mathrm{~V}\right)$ with a constant power load of $25 \mathrm{~kW}$ delivers the corresponding rated energy capacity. Table 2 shows the number of cells connected in series/parallel required to match the energy capacities specified in Table 1. While real-life CES units might utilize cells with a capacity greater than $850 \mathrm{mAh}$, a number of large lithium-ion battery packs have been designed using thousands of small cells in lieu of larger cells. For example, the Tesla Roadster electric vehicle uses 6,831 cylindrical 18650 lithium-ion cells in its $53 \mathrm{kWh}$ battery pack [39]. Furthermore, this assumption permits implementation of Chen and Rincón-Mora's experimentally-determined model parameters [7] without comprehensive information about CES battery performance characteristics or the specific design of an integrated CES system.

Table 2: We calculate the number of 850-mAh TCL PL-383562 polymer lithium-ion battery cells required to meet the CES power and energy capacity requirements specified in Table 1.

\begin{tabular}{ccc}
\hline Power Capacity & Energy Capacity & Number of Battery Cells \\
\hline $25 \mathrm{~kW}$ & $25 \mathrm{kWh}$ & 8,250 \\
$25 \mathrm{~kW}$ & $50 \mathrm{kWh}$ & 16,087 \\
$25 \mathrm{~kW}$ & $75 \mathrm{kWh}$ & 23,925 \\
\hline
\end{tabular}

In addition to an appropriate battery pack, a CES unit requires a rectifier/inverter to convert the battery's DC electricity into AC electricity appropriate for the power grid, and vice versa. We assume a one-way AC-DC 
and DC-AC energy efficiency of $93 \%$ for the inverter/rectifier bridge connecting the battery pack to the grid, consistent with values reported in the literature $[40,42]$.

Figure 2 illustrates how we use a behavioral-circuit model of a single battery cell to describe the dynamic voltage of a CES unit as a function of its instantaneous power load. In the following section, we input real-life smart grid data to the model to assess the microgrid capabilities of CES.

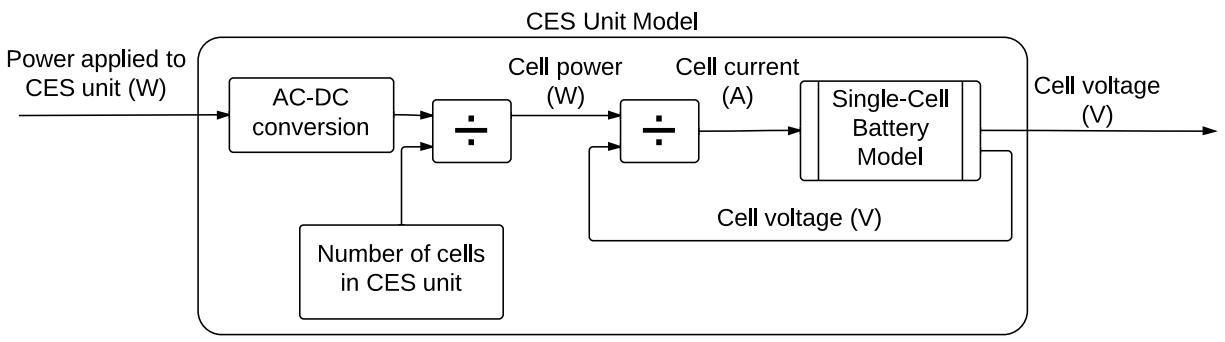

Figure 2: Our model describes the dynamic voltage of CES battery cells as a function of the power load applied to the CES unit. The power flowing to/from the grid is converted in a rectifier/inverter bridge, and then input to the CES unit's battery pack. The flow of DC power is equally divided amongst each of the battery cells, so that a single-cell battery model can be used to describe the dynamic voltage of an integrated CES system.

\section{Microgrid System Simulations}

CES and other grid-connected battery systems have the rapid powerdelivery capability required to provide frequency control for a small power system consisting of a handful of energy sources and energy sinks. This ability permits distributed energy storage to provide reliable power to an isolated microgrid during an electric outage. If distributed energy sources are available (e.g. rooftop PV panels), local battery storage can balance electricity production with demand, maintaining power quality and reliability even in the presence of intermittent energy production and consumption [43, 44].

We utilize electric load and PV energy production data collected from 21 homes in Austin, Texas to show the capabilities of CES used to power 
an islanded microgrid during an electric outage. Each of the homes has south-facing and/or west-facing rooftop PV panels installed. Table 3 contains information about each of the 21 homes' PV array size, electricity use and PV energy production. The data were recorded with one-minute time resolution. This level of resolution is important for our analysis because it allows us to approximate islanding lifetime to the nearest minute. If, for example, we used a dataset with hourly time resolution, we would only be able to reasonably approximate islanding lifetime to the nearest hour. Furthermore, the oneminute resolution of the electricity data allows us to capture the effect of large, short-duration power loads on CES. Hourly averaged electricity data, for example, would mask the occurrence of short-term power spikes. We use data from calendar year 2012 to show how seasonal and diurnal variability in electricity use and PV energy production affects the lifetime of CES powering a microgrid.

We consider a hypothetical microgrid composed of those 21 homes. Because a residential transformer typically serves 5-8 homes, we assume these 21 homes are served by three residential transformers and three CES units, with 7 homes allocated to each transformer and CES unit.

In normal operation, the microgrid freely exchanges energy with the main power grid, and we assume CES batteries are kept fully charged in anticipation of an unexpected power outage. At the precise moment that power from the grid is interrupted, CES batteries isolate the microgrid and provide backup power until they reach their minimum acceptable voltage $(3 \mathrm{~V}$ per cell), and their energy is depleted. Because islanding is an emergency function that would only occur a handful of times each year, we assume that CES can provide up to 1.5 times its rated power capacity during islanding. We consider three microgrid configurations: (1) CES is deployed in a residential neighborhood with no PV panels installed; (2) CES is deployed in a residential neighborhood where approximately half of the homes have rooftop PV panels installed; and (3) CES is deployed in a residential neighborhood where every home has rooftop PV panels installed. These three scenarios contrast the present, centralized power system with a system that has a large share of rooftop PV. Considering these three scenarios also illustrates the relative benefit of deploying energy storage in a neighborhood with a high penetration of PV panels versus a neighborhood with little or no PV penetration.

In the first scenario, the three CES units equally provide all of the electric power required by the 21 homes comprising the microgrid, essentially acting as an uninterruptible power supply (UPS) until CES batteries are depleted 


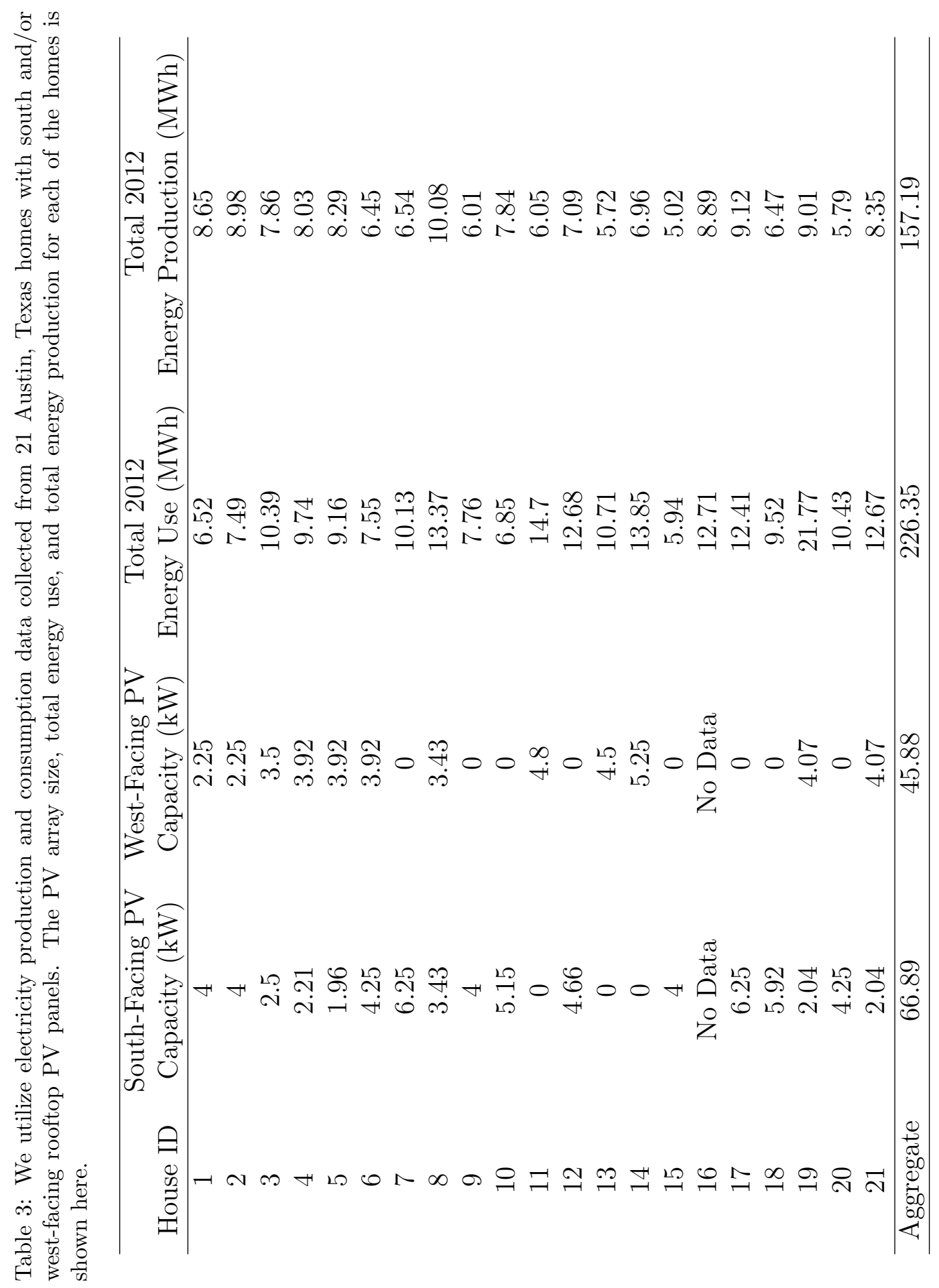


or grid power is restored.

In the second and third scenarios, the three CES units equally match electricity production from local PV systems with the electric demand of the 21 homes comprising the microgrid. During periods of high solar PV power production, CES batteries might be unable to capture solar electricity because they are fully charged. In this case, solar energy that would overload CES batteries is curtailed and lost. At all other times, CES captures solar PV electricity and powers the microgrid until CES batteries are depleted or grid power is restored. It should be noted that we assume the DER interconnection standards of IEEE 1547 [45] do not apply to our hypothetical microgrid. Presently, IEEE 1547 mandates that grid-tied solar power DC$\mathrm{AC}$ inverters automatically disconnect from the grid during an outage [45]. We assume that inverters in our hypothetical microgrid do not disconnect during an outage, so that PV electricity can be used to power the microgrid in islanded mode.

For each scenario, we simulate 8,784 independent outages corresponding to hypothetical electricity service interruptions occurring at the beginning of each hour of 2012 (a leap year). We use the results observed from these simulations to show the expected islanding lifetime of the microgrid at different times of the day during different seasons of the year.

\section{Results and Discussion}

The model developed in Section 3 is used to describe the state of CES batteries in response to a stepwise-constant power load consistent with data collected from a smart grid test bed. We model CES islanding a microgrid during hypothetical outages beginning each hour of 2012, and record the results. In the course of our study, we found that diurnal variations in electric demand and PV production have the greatest influence on the distribution of observed islanding lifetimes. Seasonal variations in demand only have a profound effect during summer months (June, July, and August), when air conditioning use significantly increases electric demand. Thus, we focus on the diurnal variation in observed islanding lifetimes to draw conclusions about the effect of utilizing transformer-level CES.

Figures 3-5 use boxplots to show the observed islanding lifetimes of the three CES units considered (25, 50, and $75 \mathrm{kWh})$. A boxplot summarizes observed data by showing upper and lower quartiles, the median, and outliers [46]. In Figures 3-5, whiskers extend up to 1.5 times the interquartile 
range of the upper and lower quartiles. Any points beyond the whiskers are considered outliers, and appear as points.

To contextualize the islanding lifetimes observed in this study, Figures 3-5 also show the average U.S. outage duration reported by electric utilities [11]. U.S. electric utilities typically quantify their electric reliability using two indices, the system average interruption frequency index (SAIFI) and the system average interruption duration index (SAIDI) [11, 47]. SAIFI indicates how often the average electricity customer experiences a sustained power interruption and is defined mathematically as in Equation 12 [47]. SAIDI indicates the total duration of interruption for the average electricity customer and is defined mathematically as in Equation 13 [47]. The customer average interruption duration index (CAIDI) can be computed from the common reliability indices SAIFI and SAIDI and is mathematically defined as in Equation 14 [47]. CAIDI represents the average time required to restore electrical service after an outage [47]. We use SAIDIs and SAIFIs reported by 123 U.S. electric utilities [11] to calculate the average U.S. CAIDI (2.73 hours).

$$
\begin{gathered}
\text { SAIFI }=\frac{\sum \text { Total Number of Customers Interrupted }}{\text { Total Number of Customers Served }} \\
\text { SAIDI }=\frac{\sum \text { Customer Interruption Durations }}{\text { Total Number of Customers Served }} \\
\text { CAIDI }=\frac{\sum \text { Customer Interruption Durations }}{\sum \text { Total Number of Customers Interrupted }}=\frac{\text { SAIDI }}{\text { SAIFI }}
\end{gathered}
$$

How often the microgrid could withstand an average-duration outage is indicated by the number of observations greater than the average of CAIDIs reported by U.S. electric utilities. We report how often various CES microgrid configurations could withstand an average outage in Table 4 .

Figure 3.a shows that $25 \mathrm{kWh}$ CES alone can withstand the vast majority of outages occurring outside the hours of 2:00-8:00 pm, when demand for electricity peaks. The median of observed islanding lifetimes only falls below the average U.S. CAIDI during this peak-demand period. Overall, $25 \mathrm{kWh}$ CES alone can withstand an average-duration U.S outage approximately $68 \%$ of the time.

Adding photovoltaic panels to the CES microgrid does not significantly increase the number of average-duration outages avoided. Comparing the 
(a) $0 \%$ of Homes with PV - 25 kWh CES

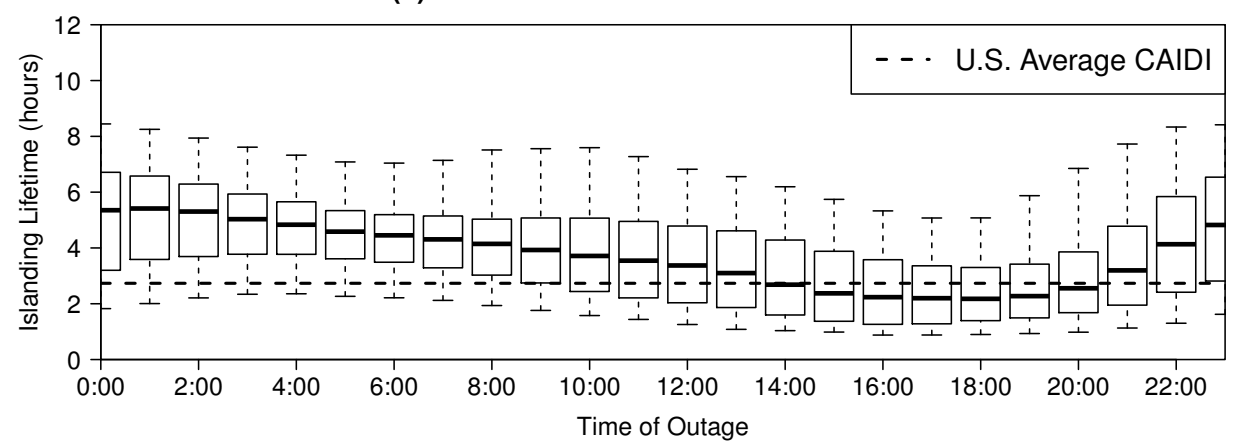

(b) $48 \%$ of Homes with PV - 25 kWh CES

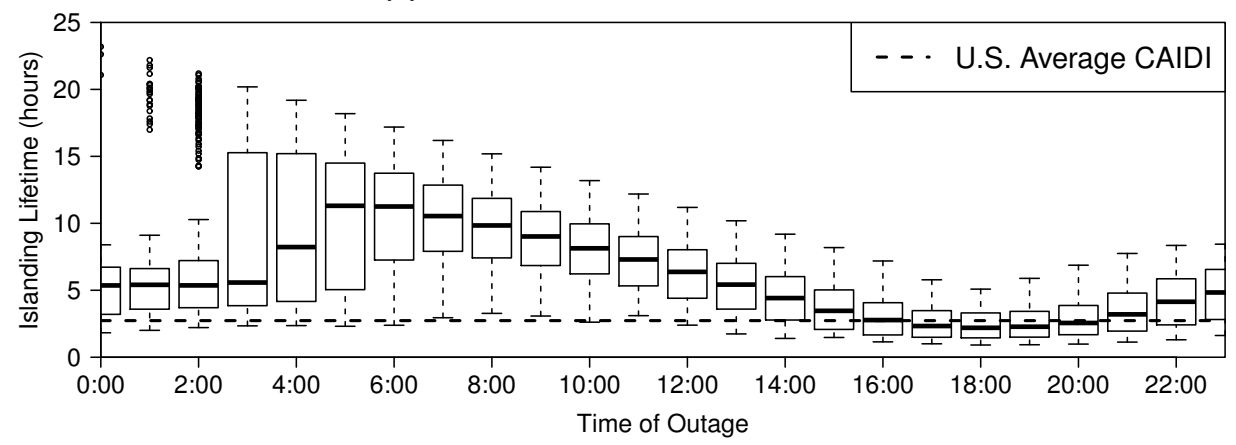

(c) $100 \%$ Homes with PV - 25 kWh CES

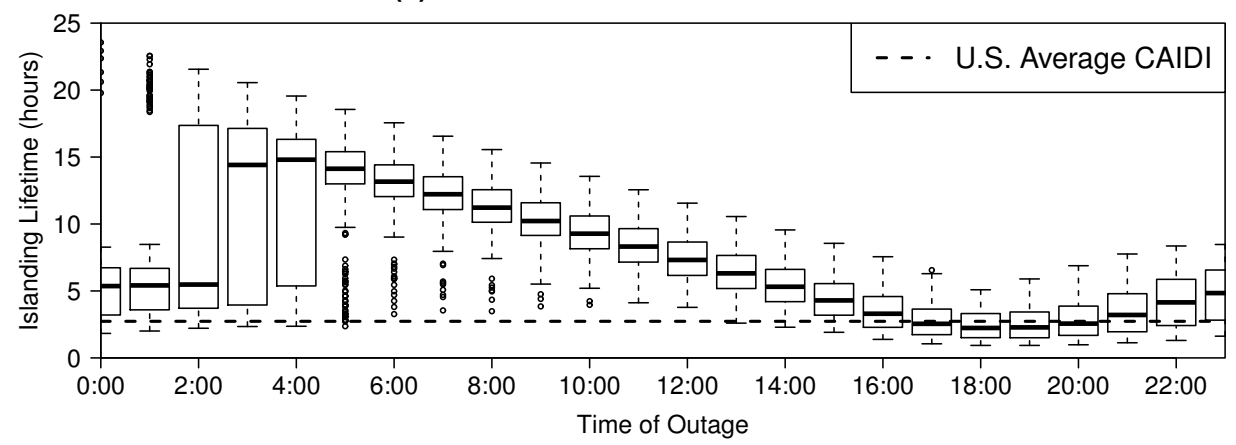

Figure 3: To gauge the reliability benefit of utilizing $25 \mathrm{kWh}$ CES, we show the distribution of islanding lifetimes observed from simulated outages occurring at the beginning of each hour. The data are contrasted with the average of CAIDIs reported by U.S. electric utilities. $25 \mathrm{kWh}$ CES alone can withstand the vast majority of outages occurring outside the hours of 2:00-8:00 pm, when electric demand peaks. The addition of PV to the microgrid significantly increases the median islanding lifetime between 3:00 am and 3:00 $\mathrm{pm}$, but does not affect the results for outages occurring after 5:00 pm. Because this cut-off point coincides with peak-demand hours, increasing $\mathrm{PV}$ penetration from $0 \%$ to $100 \%$ only increases the number of avoided average-duration outages from $68 \%$ to $82 \%$. 
(a) $0 \%$ of Homes with PV - 50 kWh CES

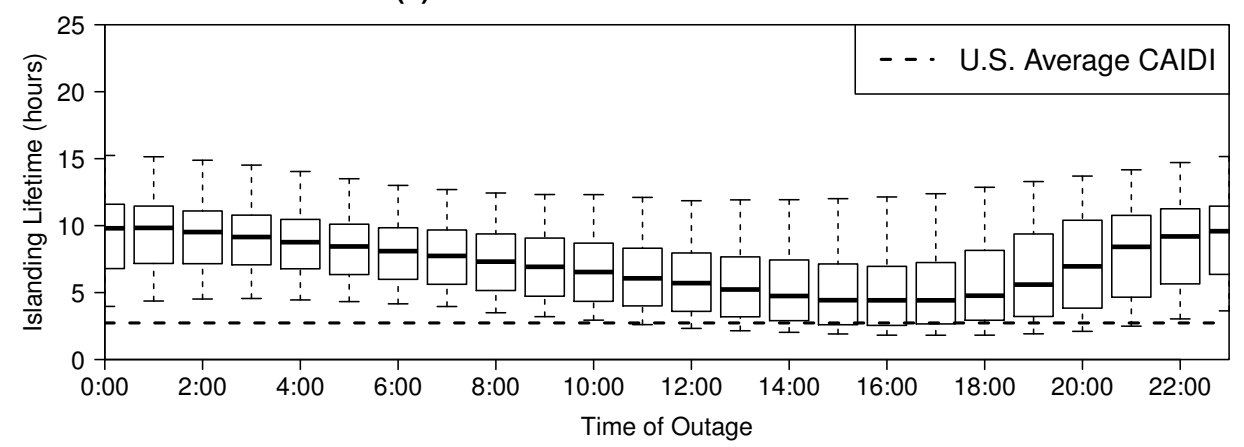

(b) $48 \%$ of Homes with PV - 50 kWh CES

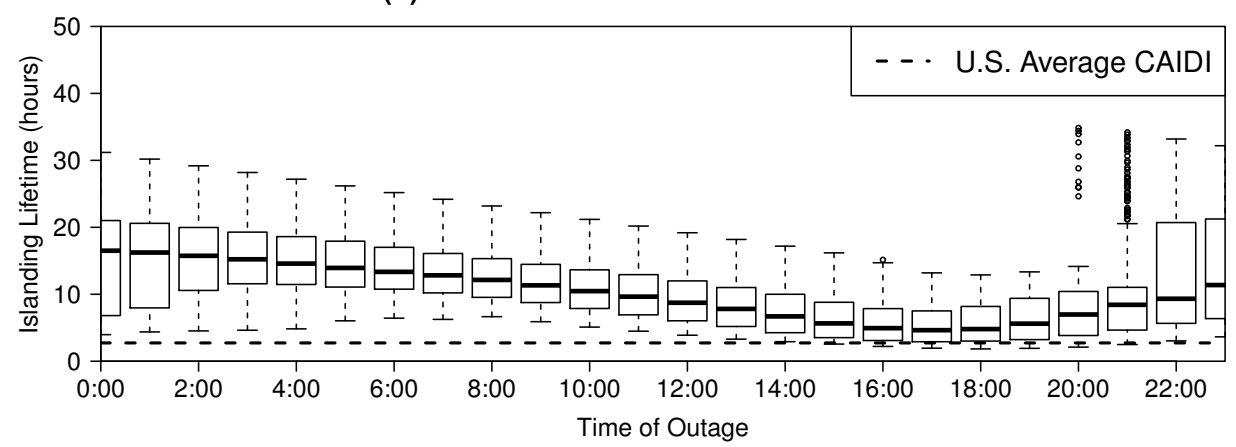

(c) $100 \%$ of Homes with PV - 50 kWh CES

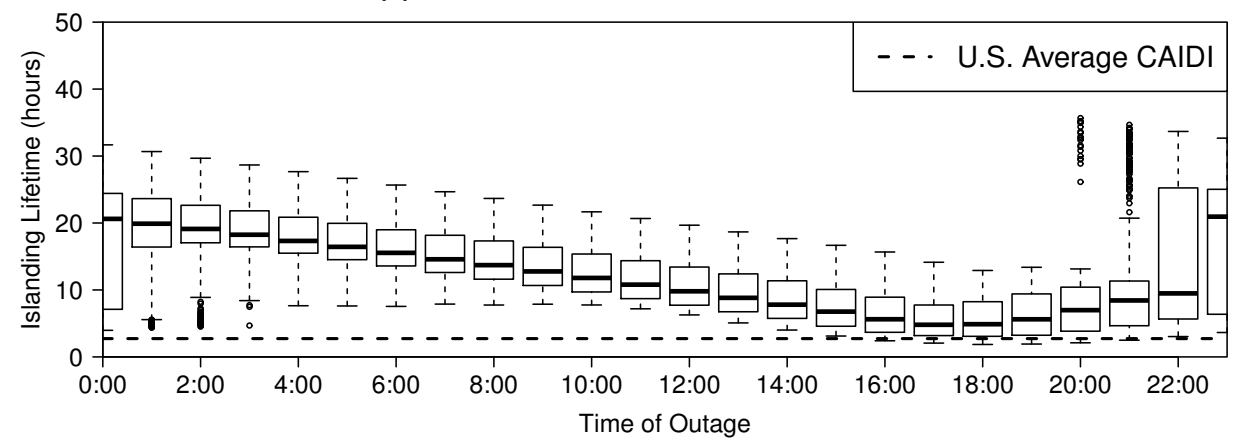

Figure 4: To gauge the reliability benefit of utilizing $50 \mathrm{kWh}$ CES, we show the distribution of islanding lifetimes observed from simulated outages occurring at the beginning of each hour. The data are contrasted with the average of CAIDIs reported by U.S. electric utilities. Increasing CES energy capacity from $25 \mathrm{kWh}$ to $50 \mathrm{kWh}$ has the greatest effect on the number of avoided average-duration outages. Overall, $50 \mathrm{kWh}$ CES alone can withstand $93 \%$ of average-duration power outages. Because PV panels do not significantly affect the results observed during peak-demand hours, increasing PV penetration from $0 \%$ to $100 \%$ only increases the percentage of avoided outages from $93 \%$ to $98 \%$. 
(a) $0 \%$ of Homes with PV - 75 kWh CES

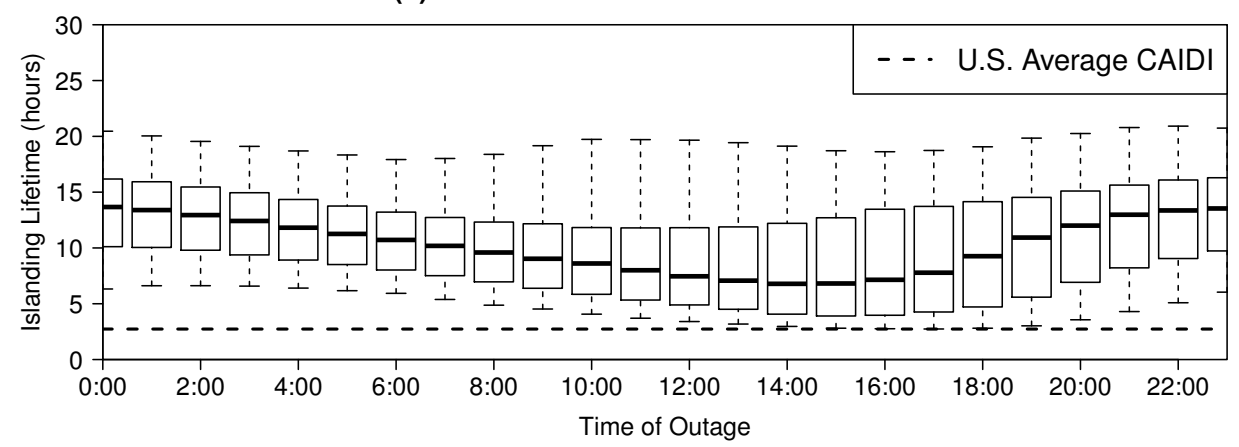

(b) $48 \%$ of Homes with PV - 75 kWh CES

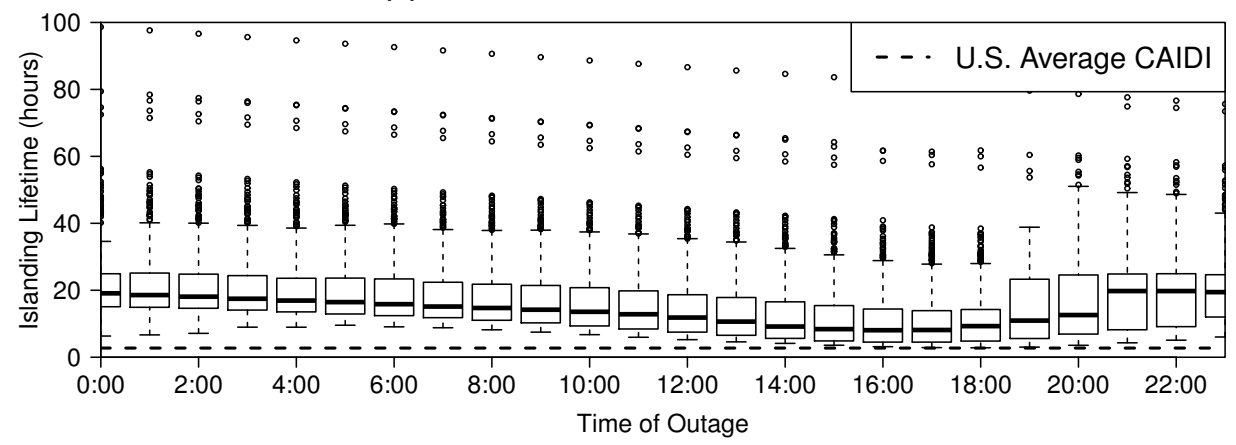

(c) $100 \%$ of Homes with PV - 75 kWh CES

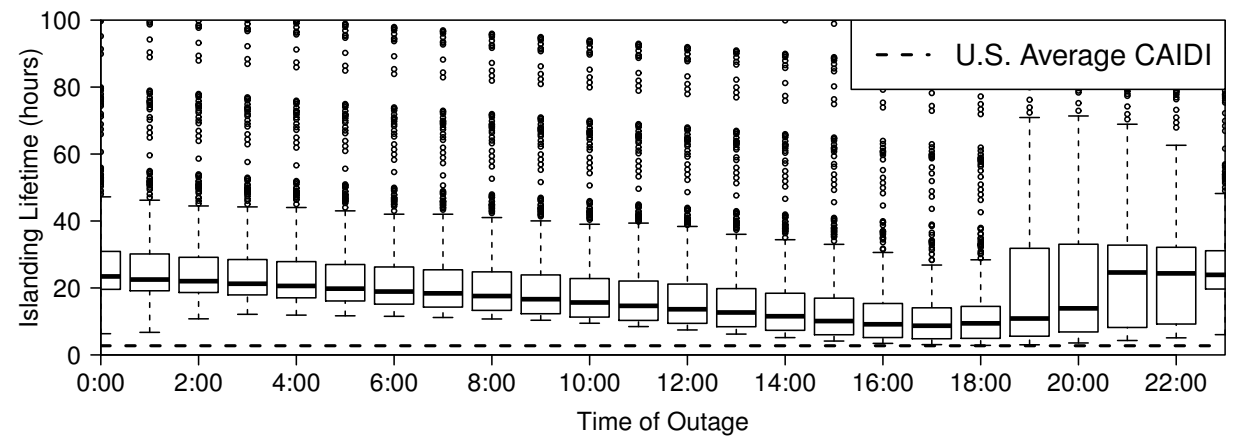

Figure 5: To gauge the reliability benefit of utilizing $75 \mathrm{kWh}$ CES, we show the distribution of islanding lifetimes observed from simulated outages occurring at the beginning of each hour. The data are contrasted with the average of CAIDIs reported by U.S. electric utilities. Increasing the energy capacity of CES to $75 \mathrm{kWh}$ gives the microgrid the ability to ride through $100 \%$ of average-duration outages, regardless of the amount of rooftop PV panels available. As was the case for $25 \mathrm{kWh}$ and $50 \mathrm{kWh} \mathrm{CES}$, the minimum observed islanding lifetimes occur during peak demand hours, when the addition of PV to the microgrid does not significantly increase islanding lifetime. Thus, increasing the PV penetration from $0 \%$ to $100 \%$ does not significantly affect the minimum islanding lifetime observed for the $75 \mathrm{kWh}$ CES microgrid. 
Table 4: We simulate microgrid islanding during thousands of independent, hypothetical outages occurring each hour of calendar year 2012, and record the observed islanding lifetimes. This table shows how often various configurations of the hypothetical, 21-home microgrid could withstand an average-duration U.S outage.

\begin{tabular}{cccc}
\hline \multicolumn{4}{c}{ Simulated islanding lifetimes longer than an average U.S. outage (\%) } \\
\hline & \multicolumn{3}{c}{ Homes with PV panels installed (\%) } \\
CES Unit Size (kWh) & 0 & 48 & 100 \\
\hline 25 & 68 & 79 & 82 \\
50 & 93 & 97 & 98 \\
75 & 100 & 100 & 100
\end{tabular}

observed islanding lifetimes shown in Figures 3.a-3.c shows that increasing the penetration of $\mathrm{PV}$ in the microgrid has almost no effect on the results for outages occurring after 5:00 pm. While this result might seem counterintuitive, it follows from the fact that electricity production from rooftop PV panels peaks early in the afternoon. On average, PV electricity production from our hypothetical 21-home microgrid peaked at approximately 1:00 pm. Furthermore, by 5:00 pm the aggregate level of PV generation fell below one third of it's peak value, on average. By 7:00pm, PV electricity production usually stopped completely. Crucially, this cut-off point occurs during peak-demand hours, when $25 \mathrm{kWh}$ CES alone cannot typically withstand an average-duration outage. Thus, even increasing PV installation from $0 \%$ of homes to $100 \%$ of homes only increases the percentage of avoided outages from $68 \%$ to approximately $82 \%$ for $25 \mathrm{kWh}$ CES.

Increasing the energy capacity of CES from $25 \mathrm{kWh}$ to $50 \mathrm{kWh}$ has the greatest effect on the number of average-duration outages avoided. Because of its greater energy capacity, $50 \mathrm{kWh}$ CES alone can power the microgrid long enough to withstand an average-duration outage $93 \%$ of the time. Figure 4.a shows that $50 \mathrm{kWh}$ CES alone could withstand all average-duration outages occurring outside the hours of 11:00 am-10:00 pm. Similar to the results for $25 \mathrm{kWh}$ CES, comparing the observed islanding lifetimes shown in Figures 4.a-4.c shows that increasing the penetration of PV in the microgrid has little effect on the results for outages occurring between 5:00 pm and 9:00 pm-coinciding with peak-demand hours. Thus, increasing the PV installation from $0 \%$ of homes to $100 \%$ of homes only increases the percentage 
of avoided outages from $93 \%$ to $98 \%$.

Increasing the energy capacity of CES from $50 \mathrm{kWh}$ to $75 \mathrm{kWh}$ gives the microgrid the ability to withstand $100 \%$ of average-duration outages, regardless of the amount of rooftop PV panels available. As was the case for $25 \mathrm{kWh}$ and $50 \mathrm{kWh}$ CES, the minimum observed islanding lifetime for $75 \mathrm{kWh}$ CES occurs during peak-demand hours, approximately 2:00-8:00 $\mathrm{pm}$. At the same time, adding PV to the $75 \mathrm{kWh}$ CES microgrid does not significantly affect the results for outages occurring between 5:00 pm and 8:00 pm. Thus, the minimum observed islanding lifetime is essentially unchanged from the addition of PV panels to the $75 \mathrm{kWh}$ CES microgrid.

We have shown that adding PV to a CES microgrid does not significantly increase how often it can withstand an average-duration outage. This result is a product of the fact that peak electric demand occurs in the early evening, when PV production is unavailable, and will not become available again for approximately 12 hours. Nevertheless, it is important to note how PV increases the median observed islanding lifetime outside peak demand hours. Figure 6 shows how increasing the amount of PV installed affects the median observed islanding lifetime for 25, 50, and $75 \mathrm{kWh}$ CES microgrids. For all CES sizes, adding PV panels to the system increases the median islanding lifetime by up to 11.6 hours from the $0 \% \mathrm{PV}$ case for outages occurring in the early morning. The addition of PV is especially beneficial for outages occurring in the early morning hours because PV generation typically exceeds electric demand in the middle of the day. After an early-morning outage, CES batteries can often discharge to meet electric demand until PV production exceeds demand, charge while PV production exceeds demand, and then discharge once again to cover electric demand into the evening - allowing CES to power downstream loads far longer than it could without PV panels present. The additional islanding lifetime provided by PV would be valuable during a major outage event lasting far longer than average, such as an outage caused by a hurricane. 
(a) 25 kWh CES

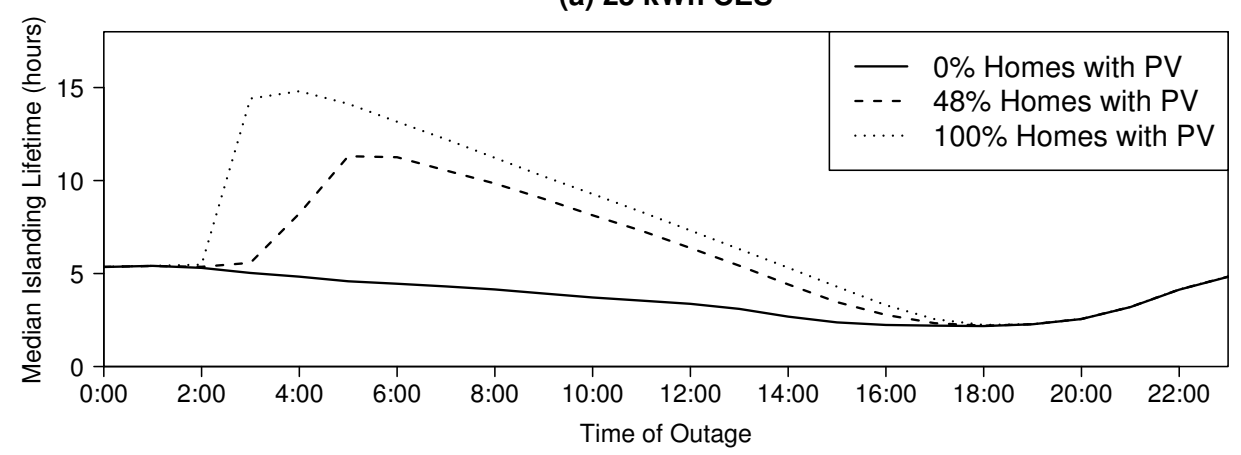

(b) $50 \mathrm{kWh}$ CES

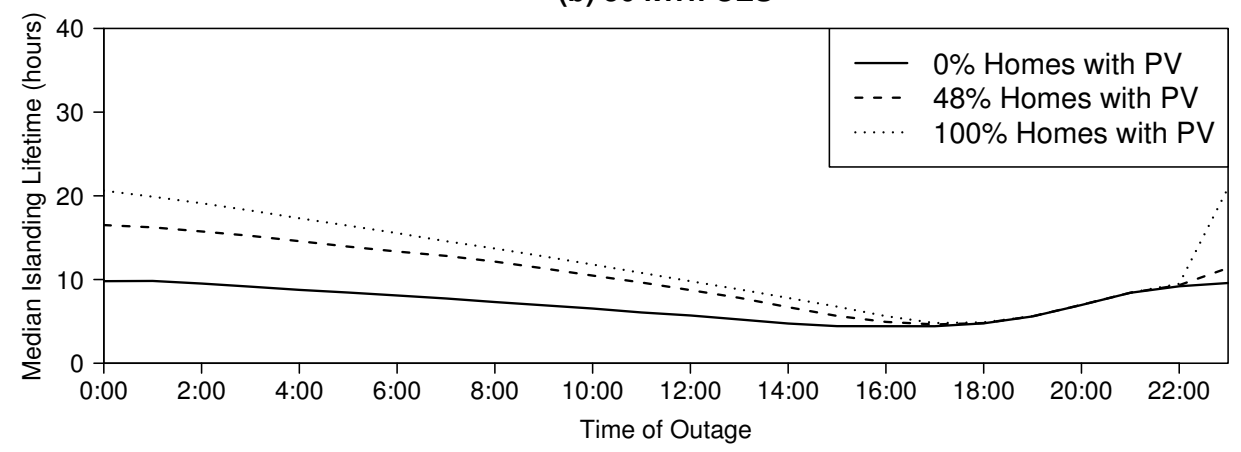

(c) 75 kWh CES

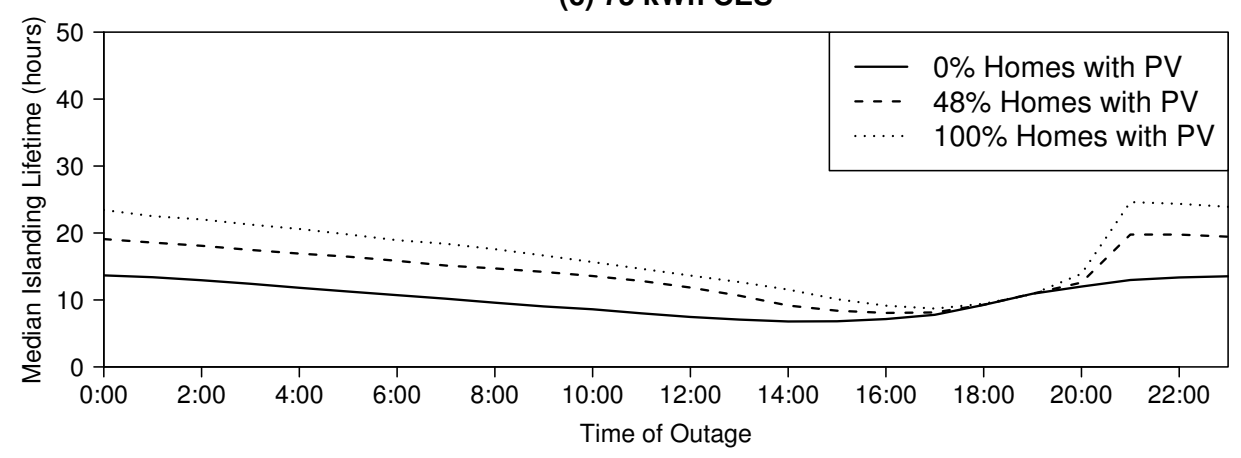

Figure 6: While adding PV to a CES microgrid does not significantly increase how often it can withstand an average-duration outage, adding PV increases the median observed islanding lifetime by up to 11.6 hours from the $0 \% \mathrm{PV}$ case for outages occurring in the early morning or late evening. The median islanding lifetime increases suddenly after 2:00 am for $25 \mathrm{kWh}$ CES, 10:00 pm for $50 \mathrm{kWh}$ CES, and 8:00 pm for $75 \mathrm{kWh}$ CES. These sudden increases are transition points where CES batteries either have enough energy to power the microgrid until solar energy production begins, or CES batteries are depleted before sunrise. 


\section{Conclusion and Future Work}

In this paper, we transformed and implemented a dynamic, system-level battery model to describe the state-dependent performance of a lithium-ion battery CES system. We then combined our CES model with one-minute electricity consumption and production data collected from an Austin, Texas smart grid test bed to simulate a microgrid operating in islanded mode. We simulated 8,784 independent islanding events occurring at the beginning of each hour of 2012, and recorded the observed islanding lifetime of the microgrid.

Our results show how the configuration of a CES microgrid affects how often it can withstand an average-duration U.S. outage, and the distribution of islanding lifetimes observed at various times of day. Based on our results, increasing the amount of PV in a CES microgrid does not significantly increase how often it can withstand an average outage, because peak electric demand occurs in the evening when PV production is low. On the other hand, increasing the amount of PV in the microgrid while retaining the CES increases the median islanding lifetime by up to 11.6 hours compared to the $0 \%$ PV case.

Based on our results, $50 \mathrm{kWh}$ CES is most likely the best choice for an average U.S. electric utility interested in using CES to increase the reliability of its power system. $50 \mathrm{kWh}$ CES alone provides enough backup energy to power downstream loads for at least the duration of an average U.S. outage $93 \%$ of the time. Furthermore, combining rooftop PV with $50 \mathrm{kWh}$ CES significantly increases the median islanding lifetime for all outages occurring outside the hours of 4:00-10:00 pm, when electric demand peaks.

$25 \mathrm{kWh}$ CES is less desirable because it can only withstand $68 \%$ of average-duration outages without PV panels present. Furthermore, adding PV panels to a $25 \mathrm{kWh}$ CES microgrid does not increase the median islanding lifetime outside the hours of 2:00 am-5:00 pm. $75 \mathrm{kWh}$ CES is also less desirable than $50 \mathrm{kWh}$ CES because it does not provide a significant incremental benefit over $50 \mathrm{kWh}$ CES. Assuming that the cost of a CES unit roughly scales with its energy capacity, it is unlikely the additional reliability benefit of $75 \mathrm{kWh}$ CES compensates for its increased cost.

Future work should explore the tradeoffs that exist for the decision to curtail electric load or deplete CES batteries. During an extended outage scenario, such as after a hurricane, it may be desirable to interrupt individual electric loads to extend the lifetime of an isolated CES microgrid. 
Quantifying the value of extending islanding lifetime versus the cost of curtailed load is a difficult exercise requiring knowledge about the preferences of electric customers within the microgrid. It would be valuable to explore these tradeoffs to reveal best practices for microgrid control during an extended outage.

\section{Acknowledgments}

This work was sponsored by Pecan Street Inc. of Austin, Texas as part of their ongoing smart grid demonstration project, which is part of the American Recovery and Reinvestment Act Smart Grid Demonstration Program administered by the U.S. Department of Energy. Special thanks to Dr. Alexis Kwasinksi for his guidance in scoping this work.

\section{References}

[1] American Electric Power, Functional Specification For Community Energy Storage (CES) Unit, Tech. rep. (2009).

[2] J. Eyer, Electric Utility Transmission and Distribution Upgrade Deferral Benefits from Modular Electricity Storage, Tech. Rep. June, Sandia National Laboratories (2009).

[3] A. A. Akhil, G. Huff, A. B. Currier, B. C. Kaun, D. M. Rastler, S. B. Chen, A. L. Cotter, D. T. Bradshaw, W. D. Gauntlett, DOE/EPRI 2013 Electricity Storage Handbook in Collaboration with NRECA, Tech. Rep. July, Sandia National Laboratories (2013).

[4] Office of Electricity Delivery and Energy Reliability, DOE Microgrid Workshop Report, Tech. rep., U.S. Department of Energy (August 2011).

[5] W. Peukert, Über die abhängigkeit der kapazität von der entladestromstärke bei bleiakkumulatoren, Elektrotechnische Zeitschrift 20 (1897) 20-21.

[6] D. Doerffel, S. A. Sharkh, A critical review of using the Peukert equation for determining the remaining capacity of lead-acid and lithium-ion batteries, Journal of Power Sources 155 (2) (2006) 395-400. doi:10.1016/j.jpowsour.2005.04.030. 
[7] M. Chen, G. Rincon-Mora, Accurate electrical battery model capable of predicting runtime and IV performance, IEEE Transactions on Energy Conversion 21 (2) (2006) 504-511.

[8] Pecan Street Inc., Pecan Street Inc. (2013).

URL http://www . pecanstreet.org/

[9] Pecan Street Inc., The Pecan Street Project (2013).

URL http://www.pecanstreet.org/projects/ smart-grid-demonstration/

[10] J. D. Rhodes, C. R. Upshaw, C. B. Harris, C. M. Meehan, D. A. Walling, P. A. Navrátil, A. L. Beck, K. Nagasawa, R. L. Fares, W. J. Cole, H. Kumar, R. D. Duncan, C. L. Holcomb, T. F. Edgar, A. Kwasinski, M. E. Webber, Experimental and data collection methods for a large-scale smart grid deployment: Methods and first results, Energydoi:10.1016/j.energy.2013.11.004.

[11] J. H. Eto, K. H. Lacommare, Tracking the Reliability of the U.S. Electric Power System: An Assessment of Publicly Available Information Reported to State Public Utility Commissions, Tech. Rep. October, Lawrence Berkeley National Laboratory (2008).

[12] F. F. Li, J. Kueck, T. Rizy, T. King, A Preliminary Analysis of the Economics of Using Distributed Energy as a Source of Reactive Power Supply, Tech. Rep. April, U.S. Department of Energy (2006).

[13] N. Hatziargyriou, H. Asano, R. Iravani, C. Marnay, Microgrids, IEEE Power and Energy Magazine 5 (4) (2007) 78-94. doi:10.1109/MPAE.2007.376583.

[14] A. Q. Huang, M. L. Crow, G. T. Heydt, J. P. Zheng, S. J. Dale, The Future Renewable Electric Energy Delivery and Management (FREEDM) System: The Energy Internet, Proceedings of the IEEE 99 (1) (2011) 133-148. doi:10.1109/JPROC.2010.2081330.

[15] M. Manfren, P. Caputo, G. Costa, Paradigm shift in urban energy systems through distributed generation: Methods and models, Applied Energy 88 (4) (2011) 1032-1048. doi:10.1016/j.apenergy.2010.10.018. URL http://linkinghub.elsevier.com/retrieve/pii/ S0306261910004204 
[16] Y.-H. Chen, S.-Y. Lu, Y.-R. Chang, T.-T. Lee, M.-C. Hu, Economic analysis and optimal energy management models for microgrid systems: A case study in Taiwan, Applied Energy 103 (2013) 145-154. doi:10.1016/j.apenergy.2012.09.023.

URL http://linkinghub.elsevier.com/retrieve/pii/ S0306261912006642

[17] A. Parisio, E. Rikos, G. Tzamalis, L. Glielmo, Use of model predictive control for experimental microgrid optimization, Applied Energy 115 (2014) 37-46. doi:10.1016/j.apenergy.2013.10.027. URL http://linkinghub.elsevier.com/retrieve/pii/ S0306261913008477

[18] M. Marzband, A. Sumper, A. Ruiz-Álvarez, J. L. Domínguez-García, B. Tomoiag?, Experimental evaluation of a real time energy management system for stand-alone microgrids in day-ahead markets, Applied Energy 106 (2013) 365-376. doi:10.1016/j.apenergy.2013.02.018.

URL http://linkinghub.elsevier.com/retrieve/pii/ S0306261913001268

[19] R. L. Fares, M. E. Webber, Dynamic Modeling of Community Energy Storage for Lifetime Estimation During Islanding, ECS Transactions 53 (7) (2013) 17-28. doi:10.1149/05307.0017ecst.

URL http://ecst.ecsdl.org/cgi/doi/10.1149/05307.0017ecst

[20] J. Newman, Electrochemical Systems, Prentice-Hall, 1972.

[21] J. Newman, K. E. Thomas, H. Hafezi, D. R. Wheeler, Modeling of lithium-ion batteries, Journal of Power Sources 119-121 (2003) 838-843. doi:10.1016/S0378-7753(03)00282-9.

[22] D. Dees, V. Battaglia, A. Bélanger, Electrochemical modeling of lithium polymer batteries, Journal of Power Sources.

[23] D. Rakhmatov, S. Vrudhula, D. Wallach, A model for battery lifetime analysis for organizing applications on a pocket computer, IEEE Transactions on Very Large Scale Integration (VLSI) Systems 11 (6) (2003) 1019-1030. doi:10.1109/TVLSI.2003.819320. 
[24] J. F. Manwell, J. G. McGowan, Lead acid battery storage model for hybrid energy systems, Solar Energy 50 (5) (1993) 399-405. doi:10.1016/0038-092X(93)90060-2.

[25] P. Rong, S. Member, M. Pedram, An Analytical Model for Predicting the Remaining Battery Capacity of Lithium-Ion Batteries, IEEE Transactions on Very Large Scale Integration (VLSI) Systems 14 (5) (2006) $441-451$.

[26] P. Pascoe, A. Anbuky, VRLA Battery Discharge Reserve Time Estimation, IEEE Transactions on Power Electronics 19 (6) (2004) 1515-1522. doi:10.1109/TPEL.2004.836680.

[27] V. Agarwal, K. Uthaichana, Development and Validation of a Battery Model Useful for Discharging and Charging Power Control and Lifetime Estimation, IEEE Transactions on Energy Conversion 25 (3) (2010) 821835 .

[28] Z. Salameh, M. Casacca, W. Lynch, A mathematical model for lead-acid batteries, IEEE Transactions on Energy Conversion 7 (1) (1992) 93-98. doi:10.1109/60.124547.

[29] L. Gao, S. Liu, R. A. Dougal, Dynamic lithium-ion battery model for system simulation, IEEE Transactions on Components and Packaging Technologies 25 (3) (2002) 495-505. doi:10.1109/TCAPT.2002.803653.

[30] M. Valvo, F. E. Wicks, R. Douglas, S. Rudiii, Development and Appliication of an Improved Equivalent Circuit Model of a Lead Acid Blattery, Proceedings of the 31st Intersociety Energy Conversion Engineering Conference.

[31] P. Mauracher, E. Karden, Dynamic Modeling of lead/acid batteries using impedance spectroscopy for parameter identification, Journal of Power Sources 67 (1997) 69-84.

[32] H. Wiegman, A. Vandenput, Battery state control techniques for charge sustaining applications, SAE transactions (1999) 1-11.

[33] S. Buller, M. Thele, Impedance-based simulation models of supercapacitors and Li-ion batteries for power electronic applications, IEEE Transactions on Industry Applications 41 (3) (2005) 742-747. 
[34] S. Gold, A PSPICE macromodel for lithium-ion batteries, The Twelfth Annual Battery Conference on Applications and Advances (1997) 215222doi:10.1109/BCAA.1997.574106.

[35] S. Hageman, Simple pspice models let you simulate common battery types, EDN 38 (1993) 117-117.

[36] B. Schweighofer, K. M. Raab, G. Brasseur, Modeling of High Power Automotive Batteries by the Use of an Automated Test System, IEEE Transactions on Instrumentation and Measurement 52 (4) (2003) 10871091.

[37] S. Abu-Sharkh, D. Doerffel, Rapid test and non-linear model characterisation of solid-state lithium-ion batteries, Journal of Power Sources 130 (1-2) (2004) 266-274. doi:10.1016/j.jpowsour.2003.12.001.

[38] B. Dunn, H. Kamath, J. M. Tarascon, Electrical Energy Storage for the Grid: A Battery of Choices, Science 334 (6058) (2011) 928-935. doi:10.1126/science.1212741.

[39] D. A. Corrigan, A. Masias, Batteries for Electric and Hybrid Vehicles, in: Linden's Handbook of Batteries, 4th Edition, McGraw Hill, 2011, Ch. 29, pp. 29.1-29.46.

[40] I. Gyuk, S. Eckroad, U.S. Department of Energy, The Electric Power Research Institute, EPRI-DOE Handbook of Energy Storage for Transmission \& Distribution Applications, Tech. Rep. December, EPRI-DOE (2003).

[41] J. Dahn, G. M. Ehrlich, Lithium-Ion Batteries, in: Linden's Handbook of Batteries, 4th Edition, McGraw Hill, 2011, Ch. 26, pp. 26.1--26.75.

[42] H. Bindner, C. Ekman, O. Gehrke, F. Isleifsson, Characterization of Vanadium Flow Battery, Tech. rep., Riso DTU National Laboratory for Sustainable Energy (2010).

[43] J. Song, M. C. Bozchalui, A. Kwasinski, R. Sharma, Microgrids availability evaluation using a Markov chain energy storage model: a comparison study in system architectures, in: PES T\&D 2012, IEEE, 2012, pp. 1-6. doi:10.1109/TDC.2012.6281637. 
[44] A. Kwasinski, Technological assessment of distributed generation systems operation during extreme events, 2012 3rd IEEE International Symposium on Power Electronics for Distributed Generation Systems (PEDG) (2012) 534-541doi:10.1109/PEDG.2012.6254054. URL http://ieeexplore.ieee.org/lpdocs/epic03/wrapper.htm? arnumber $=6254054$

[45] IEEE, Standard for interconnecting distributed resources with electric power systems, IEEE Std 1547-2003 (2003) 116doi:10.1109/IEEESTD.2003.94285.

[46] R Core Team, R: A Language and Environment for Statistical Computing, R Foundation for Statistical Computing, Vienna, Austria (2013).

URL http://www.R-project.org

[47] IEEE, IEEE guide for electric power distribution reliability indices, IEEE Std 1366-2003 (Revision of IEEE Std 1366-1998) (2004) 150doi:10.1109/IEEESTD.2004.94548. 